\title{
Fungal Population and Aflatoxin Contamination on Stored Gamma-Irradiated Nutmeg (Myristica fragrans) Kernels
}

\author{
K. Nurtjahjaa ${ }^{1,2}$, O.S. Dharmaputra ${ }^{1,3^{*}}$, W.P. Rahayu $u^{4,5}$ and R. Syarief $f^{4,5}$ \\ ${ }^{1}$ Department of Biology, Bogor Agricultural University, Jl. Agatis, Darmaga Bogor 16680, Indonesia \\ ${ }^{2}$ Department of Biology, University of Sumatera Utara, Jl. Bioteknologi No. 1, Medan 20155, Indonesia \\ ${ }^{3}$ SEAMEO BIOTROP, Jl. Raya Tajur km 6, Bogor 16134, Indonesia \\ ${ }^{4}$ Department of Food Science and Technology, Bogor Agricultural University, Darmaga, PO Box 220 Bogor 16680, Indonesia \\ ${ }^{5}$ SEAFAST Center, Bogor Agricultural University, Jl. Ulin No. 1, Darmaga Bogor 16680, Indonesia
}

\section{ARTICLE INFO}

Article history:

Received 7 January 2017

Received in revised form 8 February 2018

Accepted 12 February 2018

Keywords:

Gamma irradiation

Nutmeg kernels

Fungal population

Toxigenic

\begin{abstract}
A B S T R A C T
A study on the effectiveness of gamma irradiation at doses of 5 and $10 \mathrm{kGy}$ on fungal population, Aspergillus flavus strains, and aflatoxin $\mathrm{B}_{1}$ contamination on stored nutmeg kernels was conducted. The kernels were collected from seeds in a period of one week from the ground at North Sulawesi Province, Indonesia. Dried shelled kernels with $\pm 10 \%$ moisture content, packed in polyethylene bags at $2.1 \mathrm{~kg} / \mathrm{bag}$, were irradiated at 5 and $10 \mathrm{kGy}$ and stored at ambient temperature $\left(28{ }^{\circ} \mathrm{C}\right)$ for 2 and 4 months. Kernel moisture content, fungal population, and aflatoxin $\mathrm{B}_{1}$ were determined before and after irradiation, and after 2 and 4 months of storage. Results showed that fungal population was reduced with the increasing irradiation dose. Five species of fungi were isolated, i.e., Aspergillus flavus, A. niger, Cladosporium cladosporioides, Eurotium chevalieri, and Penicillium citrinum. A total of twelve A. flavus strains were isolated, five strains from unirradiated kernels and five and two strains from irradiated kernels at doses 5 and $10 \mathrm{kGy}$, respectively. Among these strains, $58 \%$ were capable of producing $\mathrm{L}$ sclerotia and $25 \%$ were identified as toxigenic. Kernel moisture during storage was $7.3 \%$ and no aflatoxin $\mathrm{B}_{1}$ was detected before and after irradiation, and after 2 and 4 months of storage duration.
\end{abstract}

(c) 2018 Atom Indonesia. All rights reserved

\section{INTRODUCTION}

Nutmeg (Myristica fragrans Houtt.) is one of the tropical spices that are often infected with fungi. High aflatoxin contaminations in nutmeg often indicate that the commodity is infected by Aspergillus flavus [1]. The humid tropical climate strongly supports the growth of mycotoxinproducing fungi [2]. Most of the fungal infections occur during nutmeg development, harvesting, and postharvest handling. Moreover, a majority of nutmeg is grown and harvested traditionally by subsistence farmers where harvest and storage conditions are insufficiently controlled [3]. Most nutmeg was harvested by collecting the seeds from

\footnotetext{
${ }^{*}$ Corresponding author.

E-mail address: okky@biotrop.org

DOI: https://doi.org/10.17146/aij.2018.593
}

the ground, drying them in open air on the ground, and storing them in warm humid conditions. During the drying process, the temperature and relative humidity (RH) are beyond the control of the majority of farmers. As a result, inapropriate storage of nutmegs is susceptible to attacked by fungi [3]. Dried-stored nutmeg is also hygroscopic and tends to absorb water vapor from the environment. This process leads to an increase in kernel moisture content that results in accelerated fungal infection and mycotoxin contamination.

Gamma irradiation is a physical method that can be used to reduce microbial contamination and as an alternative treatment to chemical fungicides on agricultural commodities including crops, herbs, and spices. Presently the physical treatment can be used as preservation method [4] and has been developed and approved by national legislations in 
over 60 countries worldwide and can be used to ensure food safety [5]. However, the sensitivity of fungi to irradiation depends on fungal strains [6]. At present, there are a few studies concerning the presence of field and storage fungi on nutmeg kernels. The objective was to investigate the effects of gamma irradiation on fungal population, A. flavus strains and aflatoxin $\mathrm{B}_{1}\left(\mathrm{AFB}_{1}\right)$ contamination on post-harvest nutmeg kernels after 2 and 4 months storage duration.

\section{EXPERIMENTAL METHODS}

\section{Collecting nutmeg seeds, shelling and drying}

Nutmeg seeds were obtained from plants cultivated in subsistence farms at Kauditan subdistrict, North Minahasa Regency, North Sulawesi Province, Indonesia. The seeds were collected in a period one week from the ground (naturally matured). Nutmegs with their shells was dried under sun drying followed by smoke drying $\left(45^{\circ} \mathrm{C}\right)$ until their moisture content declined to $\pm 10 \%$. Shelling and sortation of damaged kernels were conducted manually. Only intact kernels were used in this experiment.

\section{Packaging, irradiation and storing of nutmeg kernels}

Nutmeg kernels with initial moisture content of $\pm 10 \%$ were packed in polyethylene bags $(2.1 \mathrm{~kg} / \mathrm{bag})$ and sealed using a mechanical sealer. The kernels were irradiated at doses of 5 and $10 \mathrm{kGy}$ using a ${ }^{60} \mathrm{Co}$ source emitting gamma rays with an activity of $878.339 \mathrm{kCi}$ at the Center for Isotope and Radiation Application, National Nuclear Energy Agency, Jakarta, Indonesia. As control, nutmeg kernels were not irradiated. Three replicates (= 3 bags) were used for each treatment. The bags containing nutmeg kernels were then placed randomly on wooden shelves and stored for 2 and 4 months under warehouse conditions. Each bag was used to pack nutmeg kernels with different doses of gamma irradiation and different storage duration. Therefore, the number of bags containing nutmeg kernels was 27, derived from 3 (irradiation doses) $\times$ 3 (storage duration) $\times 3$ (replicates).

\section{Sampling method to obtain working sample}

Samples of nutmeg kernels were collected from each bag directly after irradiation (before storage) and subsequently after 2 and 4 months of storage. Sampling method to obtain working sample was according to Dharmaputra et al. [3]. Each sample was divided into four parts manually. One part was used as a reserved sample, while the other three parts were ground for 30 seconds at $25000 \mathrm{rpm}$ using a Mill Powder Tech Model RT-04 grinder. They were then mixed homogenously and devided into eight parts manually to determine moisture content, fungal population, and aflatoxin $\mathrm{B}_{1}$ content.

\section{Determination of kernel moisture content and fungal identification}

Moisture contents of kernels (based on wet basis) were determined by using distillation method. Three replicates were used for each sample. Fungi were isolated and enumerated by using serial dilution method, followed by pour plate method on dichloran $18 \%$ glycerol agar (DG18) which consisted of $10 \mathrm{~g} / \mathrm{L}$ glucose, $5 \mathrm{~g} / \mathrm{L}$ peptone, $1 \mathrm{~g} / \mathrm{L}$ $\mathrm{KH}_{2} \mathrm{PO}_{4}, 0.5 \mathrm{~g} / \mathrm{L} \mathrm{MgSO}_{4} .7 \mathrm{H}_{2} \mathrm{O}, 220 \mathrm{~g} / \mathrm{L}$ glycerol, $15 \mathrm{~g} / \mathrm{L}$ bacto agar, $2.0 \mathrm{mg} / \mathrm{L}$ dichloran, and $100 \mathrm{mg} / \mathrm{L}$ chloramphenicol). Plates were incubated for 7 days at room temperature $\left(28^{\circ} \mathrm{C}\right)$. A separate colony of each fungal species was isolated and cultured for 7 days at $28{ }^{\circ} \mathrm{C}$ in potato dextrose agar (PDA), Czapek yeast extract agar (CYA), or Czapek yeast extract agar with $20 \%$ sucrose (CY20S).

\section{Aspergillus flavus isolation and identification}

Every single separate colony A. flavus in every sample was isolated on aspergillus flavus and parasiticus agar (AFPA), consisting of $10 \mathrm{~g}$ peptone, $20 \mathrm{~g}$ yeast extract, $0.5 \mathrm{~g}$ ferric ammonium citrate, $100 \mathrm{mg}$ chloramphenicol, $18 \mathrm{~g}$ bacto agar, $2 \mathrm{mg}$ dichloran, and $1 \mathrm{~L}$ distilled water.

\section{Sclerotial production}

Each A. flavus strain was cultured in petri dishes $(9 \mathrm{~cm}$ diameter) containing PDA (Difco Laboratories, Sparks, US). The plates (three replicates for each strain) were incubated for 14 days at ambient temperature $\left(28^{\circ} \mathrm{C}\right)$. Sclerotia were harvested by adding $10 \mathrm{~mL}$ sterile distilled water containing $1 \mathrm{~mL} 0.05 \%$ Tween 80 into the surface of the colony in a petri dish. The colony was scrapped off using a small sterilized brush over a No. 2 Whatman filter paper. The sclerotia were placed in a beaker glass. They were then rinsed several times using tap water and then air-dried. 


\section{Determination of toxigenic and non-toxigenic $A$. flavus strains}

For determination of qualitative ability of $\mathrm{AFB}_{1}$ production, all A. flavus strains were inoculated on $10 \%$ coconut agar medium (CAM) (36 g bacto agar, $900 \mathrm{~mL}$ distilled water, and $100 \mathrm{~mL}$ coconut cream extracted from fresh shredded coconut endosperm). The medium was adjusted to $\mathrm{pH} 7.0$ using $2 \mathrm{~N} \mathrm{NaOH}$ and sterilized for 20 minutes at $15 \mathrm{lb}, 120{ }^{\circ} \mathrm{C}$. A small fragment of A. flavus colony was inoculated onto the center of a CAM culture plate in petri dish $(9 \mathrm{~cm}$ diameter) and incubated for 5 days at $28{ }^{\circ} \mathrm{C}$. The presence of yellow pigment on the reverse side of each plate was observed. The presence or absence of blue fluorescence surrounding the growing fungus colony was examined using long-wave $(365 \mathrm{~nm})$ UV light and expressed as positive or negative toxigenicity. An uninoculated plate was used for references.

\section{Quantitative analysis aflatoxin $B_{1}$}

Aflatoxin $\mathrm{B}_{1}$ analysis was conducted using high-performance liquid chromatography (HPLC) (Agilent 1260 Infinity Isocratic, Agilent Technologies, Waldbronn, Germany). Five mililiters of filtered extract in a clean vessel was diluted with $20 \mathrm{~mL} 15 \%$ Tween 20 solution and mixed well for 1 minute. The mixture was filtered through glass microfibre into a clean vessel. The mixture was loaded onto the AflaTest $^{\circledR}$ affinity column at a rate of 1-2 drops/second until air comes through column and was then washed once with $10 \mathrm{~mL}$ deionized water at a rate of 2 drops/second. A glass cuvette (VICAM \# 34000) under AflaTest ${ }^{\circledR}$ column was loaded with $1.0 \mathrm{~mL}$ HPLC grade methanol into glass syringe barrel. The AflaTest ${ }^{\circledR}$ column was eluted at a rate of 1 drop/second by passing the methanol through the column. One milliliter of eluated sample collected in a glass cuvette was added with $1 \mathrm{~mL}$ deionized water. Afterward, 20-100 $\mu \mathrm{L}$ of the result was injected into HPLC.

\section{RESULTS AND DISCUSSION}

Nutmeg kernels collected in a period of one week on the ground were infected by field and storage fungi. Cladosporium cladosporioides is a field fungus, while Aspergillus flavus, Aspergillus niger, Eurotium chevalieri, and Penicillium citrinum are storage fungi. Cladosporium cladosporioides and Penicillium citrinum were the most predominant field and storage fungi, respectively. Both of those species were still viable after 4 months storage duration at irradiation $10 \mathrm{kGy}$ (Table 1).

Table 1. Fungal population on non-gamma irradiated and gamma-irradiated on-storage nutmeg kernels

\begin{tabular}{|c|c|c|c|c|c|c|c|c|c|}
\hline \multirow[t]{3}{*}{ Fungal species } & \multicolumn{9}{|c|}{$\begin{array}{c}\text { Gamma irradiation doses (kGy)/storage } \\
\text { duration (months)/fungal population } \\
\left(\log \mathrm{cfu} \mathrm{g}^{-1}\right)\end{array}$} \\
\hline & \multicolumn{3}{|c|}{ No irradiation } & \multicolumn{3}{|c|}{$5 \mathrm{kGy}$} & \multicolumn{3}{|c|}{$10 \mathrm{kGy}$} \\
\hline & 0 & 2 & 4 & 0 & 2 & 4 & 0 & 2 & 4 \\
\hline Aspergillus flavus & 0.5 & 1.1 & 0 & 0.5 & 0.8 & 0.8 & 0.5 & 0.5 & 0 \\
\hline A. niger & 0.5 & 1.0 & 1.1 & 0 & 0 & 0.5 & 0 & 0 & 0 \\
\hline $\begin{array}{l}\text { Cladosporium } \\
\text { cladosporioides }\end{array}$ & 1.8 & 0 & 0.8 & 0 & 0.5 & 1.2 & 0 & 0 & 1.1 \\
\hline Eurotium chevalieri & 1.3 & 0.8 & 1.4 & 0 & 0 & 0 & 0 & 0 & 0 \\
\hline $\begin{array}{l}\text { Penicillium } \\
\text { citrinum }\end{array}$ & 2.0 & 0.8 & 2.0 & 0 & 0 & 0 & 0 & 0 & 0.8 \\
\hline
\end{tabular}

Irradiation at doses of 5 and $10 \mathrm{kGy}$ reduce the population of all fungal species. However, each species has different viability. Irradiation dose of $10 \mathrm{kGy}$ is effective to kill all fungi except A. flavus. The presence of $A$. flavus on irradiated kernels after 4 months of storage indicate their resistance on irradiaton. Allam and El-Zaher [7] reported that Aspergillus flavus is one of the Aspergilli that are relatively resistant to gamma ray. The dry condition of kernels during irradiation process suggested their spores' resistance on irradiation.

Among storage fungi that might produce aflatoxin $\mathrm{B}_{1}$, we found twelve strains of A. flavus. They consist of five strains isolated from unirradiated kernels before and after 2 months of storage and the other five and two strains were isolated on stored kernels after 2 and 4 months at irradiation doses of 5 and $10 \mathrm{kGy}$, respectively. The codes of the strains are presented on Table 2.

Table 2. Codes of A. flavus strains isolated from unirradiated and gamma-irradiated at doses 5 and $10 \mathrm{kGy}$ during 0,2 and 4 months of storage

\begin{tabular}{lccc}
\hline \multirow{2}{*}{$\begin{array}{l}\text { Gamma irradiation } \\
\text { doses (kGy) }\end{array}$} & \multicolumn{3}{c}{ Storage duration (months) /A. flavus } \\
& strains code \\
\cline { 2 - 4 } & 0 & 2 & 4 \\
\hline 0 (no irradiation) & $\mathrm{AFS} 0 \mathrm{R} 0$ & $\mathrm{AFS} 2{ }_{1} \mathrm{R} 0$ & \\
& & $\mathrm{AFS}{ }_{2} \mathrm{R} 0$ & \\
& & $\mathrm{AFS}{ }_{3} \mathrm{R} 0$ & \\
& & $\mathrm{AFS} 2{ }_{4} \mathrm{R} 0$ & \\
5 & $\mathrm{AFS} 0 \mathrm{R} 5$ & $\mathrm{AFS}{ }_{1} \mathrm{R} 5$ & $\mathrm{AFS} 4{ }_{1} \mathrm{R} 5$ \\
& & $\mathrm{AFS}{ }_{2} \mathrm{R} 5$ & $\mathrm{AFS} 4{ }_{2} \mathrm{R} 5$ \\
10 & $\mathrm{AFS} 0 \mathrm{R} 10$ & $\mathrm{AFS} 2 \mathrm{R} 10$ & \\
\hline
\end{tabular}

$\mathrm{AF}=$ A. flavus $; \mathrm{S}=$ storage duration: $0,2,4$ months and number strains found (subscript); $\mathrm{R}=$ irradiation doses: no irradiation $(0), 5$ and $10 \mathrm{kGy}$

Each A. flavus strain (Table 3) varies in morphological characteristics such as sclerotial production, seriation of conidial head, and toxigenicity. 
A previous study reported that strains of A. flavus consist of biseriate and uniseriate strains [8]. However, most uniseriate and L strains were observed in this study. Fifty-eight percent ( 7 of 12) A. flavus strains isolated from unirradiated and irradiated kernel formed Large (L) sclerotia and 5 of 12 strains were non-sclerotial producers as it was reported in other studies [8].

Table 3. Morphological characteristics and toxigenicity of A. flavus strains isolated from unirradiated and irradiated nutmeg kernels

\begin{tabular}{|c|c|c|c|c|}
\hline $\begin{array}{l}\text { A. flavus } \\
\text { strains }\end{array}$ & $\begin{array}{l}\text { Diameter }(\mu \mathrm{m}) \\
\text { type sclerotia* }\end{array}$ & $\begin{array}{l}\text { Uniseriate/ } \\
\text { biseriate }\end{array}$ & $\begin{array}{l}\text { Fluorescence } \\
\text { in CAM }\end{array}$ & Toxigenicity \\
\hline AFSOR0 & NSP & $\mathrm{b}$ & + & toxigenic \\
\hline $\mathrm{AFS} 2{ }_{1} \mathrm{R} 0$ & $700-800(\mathrm{~L})$ & $\mathrm{u}$ & - & non-toxigenic \\
\hline $\mathrm{AFS} 2{ }_{2} \mathrm{R} 0$ & $520-580(\mathrm{~L})$ & $\mathrm{u}$ & - & non-toxigenic \\
\hline $\mathrm{AFS} 2{ }_{3} \mathrm{R} 0$ & $520-540(\mathrm{~L})$ & $\mathrm{u}$ & - & non-toxigenic \\
\hline $\mathrm{AFS} 2{ }_{4} \mathrm{R} 0$ & $510-800(\mathrm{~L})$ & $\mathrm{u}$ & - & non-toxigenic \\
\hline AFS0R5 & NSP & $\mathrm{u}$ & - & non-toxigenic \\
\hline $\mathrm{AFS} 2_{1} \mathrm{R} 5$ & NSP & $\mathrm{u}$ & + & toxigenic \\
\hline $\mathrm{AFS} 2{ }_{2} \mathrm{R} 5$ & NSP & $\mathrm{u}$ & - & non-toxigenic \\
\hline $\mathrm{AFS} 4_{1} \mathrm{R} 5$ & NSP & $\mathrm{u}$ & - & non-toxigenic \\
\hline $\mathrm{AFS}_{4}{ }_{2} \mathrm{R} 5$ & $560-580(\mathrm{~L})$ & $\mathrm{u}$ & + & toxigenic \\
\hline AFS0R10 & $520-540(\mathrm{~L})$ & $\mathrm{b}$ & - & non-toxigenic \\
\hline AFS2R10 & $520-560(\mathrm{~L})$ & $\mathrm{u}$ & - & non-toxigenic \\
\hline
\end{tabular}

$\mathrm{L}=($ Large) sclerotia, $\mathrm{NSP}=$ non-sclerotial producer,,+- = fluorescence no fluorescence

*sclerotia were observed after incubation for 2 weeks on potato dextrose agar at $28{ }^{\circ} \mathrm{C}$

Odhiambo et al. [9] differentiate toxigenic and non-toxigenic $A$. flavus strains based on yellow pigment formation using PDA medium. Our results found that $25 \%$ (three of twelve) A. flavus strains, namely AFS0R0, AFS $2{ }_{1} \mathrm{R} 5$, and $\mathrm{AFS} 4_{2} \mathrm{R} 5$, were $\mathrm{AFB}_{1}$ producers or toxigenic strains (Table 3) as indicated by the presence of yellow pigment on the reverse side of the colony after 5 days of incubation at $28{ }^{\circ} \mathrm{C}$ in CAM medium. In addition, toxigenic strains in CAM medium were indicated by the presence of blue fluorescence surrounding the colony and very light yellowish brown (beige) at the colony edge under 365-nm UV light.

Kernel moisture content and $\mathrm{AFB}_{1}$ contamination before and after iradiation and after 2 and 4 months of storage to all samples are shown on Table 4. Our results showed that no $\mathrm{AFB}_{1}$ production was detected. The presence of three toxigenic strains (AFS0R0, AFS2 ${ }_{1} \mathrm{R} 5, \mathrm{AFS}_{2} \mathrm{R} 5$ ) in kernels do not necessarily indicate that the strains are aflatoxin producers. We assumed that the strains were not able to metabolize under the dry condition of the kernels during storage.
Table 4. Moisture content and $\mathrm{AFB}_{1}$ concentration on irradiated and unirradiated nutmeg kernels after 0,2 and 4 storage duration

\begin{tabular}{lllllllllll}
\hline $\begin{array}{l}\text { Kernels } \\
\text { Parameter }\end{array}$ & \multicolumn{8}{c}{$\begin{array}{c}\text { Gamma irradiation dose (kGy) / storage duration } \\
\text { (month) }\end{array}$} \\
\cline { 2 - 10 } & \begin{tabular}{l} 
No irradiation \\
\cline { 2 - 9 }
\end{tabular} & 7.4 & 7.5 & 6.7 & 7.2 & 7.7 & 6.9 & 6.9 & 7.8 & 7.3 \\
\hline $\begin{array}{l}\text { Moisture content } \\
(\% \text { w.b) }\end{array}$ & ND & ND & ND & ND & ND & ND & ND & ND & ND \\
$\begin{array}{l}\text { AFB } \\
(\mathrm{ppb})\end{array}$
\end{tabular}

$\mathrm{ND}=$ not detected; limit of detection $<0.92 \mathrm{ppb}$

Packing kernels in polyethylene bags maintain kernel moisture $(7.0 \pm 0.3 \%)$ and inhibit fungal growth and aflatoxin production. In addition, the predominance of non-toxigenic $\mathrm{L}$ strains might prevent aflatoxin production by toxigenic strains [10].

\section{CONCLUSION}

A gamma irradiation dose of up to $10 \mathrm{kGy}$ on dry nutmeg is effective to kill fungi except A. flavus. Twelve A. flavus strains were isolated. Among these, $25 \%$ were characterized as aflatoxin producers. Five of the strains were found on unirradiated kernels and five and two strains were found on kernels irradiated at doses of 5 and $10 \mathrm{kGy}$, respectively. No aflatoxin $\mathrm{B}_{1}$ was found on dried irradiated and unirradiated kernels packed in polyethylene bags during storage of up to 4 months.

Reducing fungal population by integrated established system for the safe handling such as drying and proper storage before irradiation might be required to increase the effectiveness of irradiation.

\section{ACKNOWLEDGMENT}

The results reported herein were made possible by the Directorate General Higher Education, Ministry of Research and Technology Republic of Indonesia Grant No. 017/SP2H/LT/DRPM/II/2016 and Phytopathology Laboratory, SEAMEO BIOTROP Bogor - Indonesia for research facilities. We also thank Ina Retnowati for technical assistance.

\section{REFERENCES}

1. Anonymous, Discussion Paper on the Development of Maximum Levels for Mycotoxin in Spices and Possible Prioritization of Work, Tenth session, 4-8 April, in: CODEX Alimentarius Commission / FAO / WHO, 
Rotterdam, The Netherlands (2016) 1. www.codexalimentarius.org

2. Anonymous, Discussion Paper on the Establishment of a Maximum Level for Aflatoxin $B_{1}$ and Total Aflatoxins in Nutmeg and Associated Sampling Plan (Prepared by Indonesia), Eighth session, 31 March-4 April, in: CODEX Alimentarius Commission / FAO / WHO, The Hague, Netherlands (2014) 1. www.codexalimentarius.org

3. O.S. Dharmaputra, S. Ambarwati, I. Retnowati et al., Biotropia 22 (2015) 129.

DOI:http://dx. doi.org/10.11598/btb. 2015.22. 2.458 .

4. M.S. Yusuf, I. Wulandari, L. Amelia et al., Pharmacogn J. 9 (2017) 239.

DOI: 10.5530/pj.2017.2.40.
5. B. Maherani, F. Hossain, P. Criado et al., Trends Foods 5 (2016) 1. DOI:10.3390/foods55040079.

6. A.H.A. Al-Abdallal, J. Food, Agriculture and Environ. 12 (2014) 77. www.world-food.net

7. N.G. Allam and H.F.A. El-Zaher, Afr. J. Biotechnol. 11 (2012) 6566. DOI: $10.5897 / A J B 11.4136$.

8. S.A. Okoth, B. Nyongesa, V. Joutsjoki et al., Adv. Microbiol. 6 (2016) 47.

DOI: dx.doi.org/10.4236/aim.2016.61005.

9. B.O. Odhiambo, H. Murage and Wagara I.N, Egerton J. Sci. and Technol. 14 (2014) 61.

10. K.C. Ehrlich, Frontiers in Microbiol. 5 (2014) 1. DOI: $10.3389 /$ fmicb.2014.00050. 